\title{
Nutrient deposition partitioning and priorities between body compartments in two size classes of rainbow trout in response to feed restriction
}

\author{
Guillaume Salze ${ }^{1,2 *}$, Helene Alami-Durante ${ }^{3}$, Shai Barbut ${ }^{4}$, Massimo Marcone $^{4}$ and \\ Dominique P. Bureau ${ }^{1}$ \\ ${ }^{1}$ Department of Poultry and Animal Science, University of Guelph, Guelph, Ontario, Canada N1G 2W1 \\ ${ }^{2}$ School of Fisheries, Aquaculture, and Aquatic Sciences, 203 Swingle Hall, Auburn University, Auburn, AL 36849, USA \\ ${ }^{3}$ INRA, UR 1067 Nutrition Métabolisme Aquaculture, Aquapôle F-64310, St-Pée-sur-Nivelle, France \\ ${ }^{4}$ Department of Food Science, University of Guelph, Guelph, Ontario, Canada N1G 2W1
}

(Submitted 5 February 2013 - Final revision received 10 September 2013 - Accepted 18 October 2013 - First published online 13 December 2013)

\section{Abstract}

Adaptations in growth dynamics in fish, i.e. how fish prioritise tissue accretion between organs, remains poorly understood. In the present study, we investigated the effects of graded feed restriction levels on nutrient deposition in $1.3 \mathrm{~g}$ fingerlings and $70 \mathrm{~g}$ juveniles. At the whole-body level, highly restricted juveniles strove to maintain body protein while mobilising lipid reserves and compensating for mass loss by increasing water content. In contrast, fingerlings maintained body water and energy contents. Additionally, we investigated deposition patterns in four body compartments (red and white axial muscles, viscera and rest of the carcass) in juveniles and changes in the cellularity of the white and red muscles in fingerlings. We provide evidence of priorities in growth and nutrient deposition in body compartments in response to low feeding levels. In juveniles, feed intake (FI) primarily affected the white muscle, while the red muscle and the viscera appeared to be preserved. Specific proteins ( 45 and $173 \mathrm{kDa}$ ) were preferentially deposited in the white muscle, while others (22 and $32 \mathrm{kDa}$ ) were preferentially mobilised. In fingerlings' muscle anterior to the anus, the cross-sectional surface areas increased with increasing FI in a logarithmic fashion in the white muscle, and in linear fashion in the red muscle. The maximum diameter of white fibres decreased linearly with fish length, while that of red fibres remained stable. This suggests an adaptation mechanism by decreasing white muscle hyperplasia in favour of hypertrophy when feed is restricted. Overall, these results indicate some mechanisms by which fish cope with low food availability. Our findings also suggest different adaptation strategies employed by fish of different body weights.

\section{Key words: Nutrient deposition: Myofibres: Muscle proteins: Growth dynamics}

Regardless of being in the wild or in controlled culture conditions, quantitative limitations of food or feed intake (FI) are relatively common in fish. Feeding costs often represent half of fish farms' operating costs; therefore, it is common for farmers to restrict feeding when facing logistical or financial hurdles. Other causes for the variability in access to food/feed include seasonal variations, disease outbreak, poor water quality, poor feed palatability and nutrient deficiencies. Animals need nutrients and energy to sustain their basal metabolism, enable movement, support their immune system, grow in size and produce gametes to establish the next generation. Contrary to higher vertebrates, fish are characterised by their particularly plastic growth: it is a process that is decidedly responsive to environmental factors while also being highly regulated at the level of organs and body constituents ${ }^{(1)}$. When quantitatively restricted, fish will prioritise the available resources between the abovementioned functions: there is active adaptation as well as utilisation of available dietary nutrients and internal reserves to cover essential needs and achieve metabolic targets ${ }^{(2)}$. Hence, the consequences of malnutrition depend not only on its severity and duration, but also on the priorities of the individual at a given time, i.e. life stage, health and reproductive status. However, although the far-reaching consequences of feed restriction on the physiology of animals (e.g. puberty ${ }^{(3-5)}$ ) are easily conceivable, our current level of understanding remains mostly empirical. There is a need for more comprehensive and mechanistic approaches to better understand and predict these adaptive changes in a more rational manner.

Abbreviations: CP, crude protein; FE, feed efficiency; FI, feed intake; TGC, thermal-unit growth coefficients.

*Corresponding author: G. Salze, email gsalze@auburn.edu 
Naturally, the most-studied consequence of feed restriction is its limiting effect on growth (increase in mass) ${ }^{(6)}$. For example, feed-restricted fish often, but not always ${ }^{(7)}$, have a lower condition factor $K$, indicating a change in body shape ${ }^{(8-10)}$. This indicates that growth and development of some organs have priority over those of others, as also observed in humans ${ }^{(11)}$, other mammals ${ }^{(12-14)}$ and birds ${ }^{(15,16)}$. Moreover, feeding regimens affect nutrient utilisation. Highly and poorly fed animals typically present different body compositions; higher intake generally leads to fatter fish ${ }^{(17,18)}$. A negative relationship is characteristically observed between lipid and water contents as one is deposited by substituting the other ${ }^{(19-21)}$. However, body protein content remains remarkably constant and correlated with body weight ${ }^{(22-24)}$. The deposition of proteins and lipids is achieved through different processes ${ }^{(25)}$; highly fed fish retain more lipid than protein, whereas fish fed a maintenance ration (metabolisable energy allocation resulting in zero energy gain) still have positive protein retention but mobilise body lipids.

Further reduction of rations may result in cachexia, a loss of lean mass compensated by an increase in water content in an attempt to maintain body weight. Pushing restrictions to the point of starvation will lead to wasting, where nutrient intake becomes so limiting that water accumulation can no longer compensate for the loss of cellular mass ${ }^{(26)}$. Thus, organisms develop different coping mechanisms according to the degree of feed restriction. It should be noted that despite the apparent similarity of sequential utilisation of nutrient storage during starvation ${ }^{(27,28)}$, the metabolic adaptations to feed restriction are different and should not be directly compared.

Few studies have detailed the differences in growth dynamics between growth stages. Dumas et $a l^{(29)}$ showed three distinct growth stanzas in rainbow trout, which were characterised by different growth trajectories. It can be hypothesised that these stanzas can be further described by characteristic nutrient deposition patterns. Likewise, few studies have considered nutrient composition and deposition at the organ level and their relative growth. The viscera comprise organs that are central to essential physiological functions, such as digestion and nutrient processing, osmoregulation, ion and gas exchange, and immunity. These organs are metabolically costly to maintain and thus are tightly regulated by FI: enzyme activities and viscera somatic index are noticeably decreased during starvation ${ }^{(30,31)}$. Additionally, skeletal muscle is not a homogeneous tissue as it contains, among other cell types, both red and white fibres. The former are typically characterised by aerobic metabolism and high physical endurance, while the contraction of the latter is faster, but their glycolysis-based metabolism makes them more susceptible to fatigue. Different metabolism paradigms imply a situation-dependent usage, typically long-term $v$. brisk, short-term efforts. Kiessling et al. $^{(32)}$ observed a decrease in the mean cross-sectional surface area of both white and red fibres with decreasing rations in rainbow trout. They found that the size distribution of white fibres was tightly correlated with body length, while that of red fibres was only changed in response to very restricted rations.
Thus, evidence suggests that feeding regimens influence growth and nutrient deposition in different body organs or groups of organs. Understanding nutrient deposition patterns is key: from a biological perspective, they reflect the animal's priorities when matching available resources with metabolic targets and may affect lower-priority functions (e.g. immunity or reproduction as mentioned above). From a commercial perspective, tissues have different economic values (fillet $v$. viscera $v$. skeleton), and composition is known to determine texture and other physical characteristics that are critical to the food processing industry. However, there are limited quantitative data from which precise predictions of organ growth patterns and nutrient partitioning can be made.

By definition, energy-centred models cannot predict nutrientspecific deposition and are limited in their ability to predict feed efficiency (FE) under a wide variety of conditions ${ }^{(25,33)}$. In the present study, we evaluated the influence of feed restriction on growth at the individual and tissue levels in rainbow trout. We also hypothesised that trout in different growth stages (fingerlings and juveniles) will prioritise nutrient accretion differently in a context of limited access to feed. Specifically, in juveniles, we investigated the patterns of nutrient deposition in four tissue compartments: the red and white muscles, viscera and the rest of the carcass. In fingerlings, we describe the response to feed restriction by analysing red and white muscle fibre hypertrophy and hyperplasia.

\section{Materials and methods}

\section{Growth trial}

All the experimental procedures were carried out in accordance with the University of Guelph Animal Utilization Protocol (\#07R068). Experimental rainbow trout (Oncorbynchus mykiss) were obtained from the Alma Aquaculture Research Station. They were reared in a semi-recirculating system, equipped with twenty-four 46-litre tanks supplied with well water. Temperature was regulated between 12 and $13^{\circ} \mathrm{C}$. Each tank was equipped with a sloped bottom and an air stone to provide aeration and help solid removal. The water was then directed to a settling sump followed by mechanical (foam) and biological (fixed-bed) filtration. Routine monitoring included temperature and mortalities (daily) and total $\mathrm{NH}_{3}-\mathrm{N}$ (weekly). Photoperiod was automatically controlled and set to a $12 \mathrm{~h}$ light $-12 \mathrm{~h}$ dark cycle.

The experiment was set up as a $2 \times 4$ factorial design: two size classes and four feeding rations, namely 100, 75, 50 and $25 \%$ of satiation. Size classes and feeding rations were randomly allocated to thirty-six tanks (three tanks per ration and per size class). The initial body weights of the two size groups were 68.9 (SD 1.0) g (juveniles) and 1.3 (SD 0.0) g (fingerlings), respectively. The juveniles were stocked at fifteen fish per tank, while the fingerlings were stocked at 150 fish per tank. Fish size and ration were randomly allocated to available tanks. All fish were fed the same diet, which was a high-quality extruded feed of known composition (open feed formulation MNR-08HS; Table 1) manufactured by Corey Feed Mill for the Ontario Ministry of Natural 
Table 1. Formula and chemical composition of the diet (open feed formulation MNR-08HS)

\begin{tabular}{|c|c|c|c|}
\hline & $\%$ (as-is) & & \\
\hline Ingredients & & Proximate composition (analysed) & \\
\hline Fishmeal (>68\% CP) & $24 \cdot 00$ & DM (\%, as-is) & $95 \cdot 2$ \\
\hline Brewer's dried yeast $(45 \% \mathrm{CP})$ & 4.00 & $\mathrm{CP}(\%)$ & $47 \cdot 1$ \\
\hline Wheat & $16 \cdot 06$ & Lipid (\%) & $19 \cdot 8$ \\
\hline Maize gluten meal $(60 \% \mathrm{CP})$ & $18 \cdot 00$ & Ash (\%) & $6 \cdot 7$ \\
\hline Feather meal $(>75 \% \mathrm{CP})$ & $7 \cdot 00$ & Gross energy (kJ/g) & $22 \cdot 7$ \\
\hline Poultry by-product meal (>65\% CP) & $10 \cdot 50$ & Digestible nutrients and energy (calculated) & \\
\hline Soyabean meal, dehulled (48\% CP) & 4.00 & Digestible DM (\%) & $73 \cdot 4$ \\
\hline Lys- $\mathrm{HCl}$ (>75\% Lys) & 0.50 & Digestible protein (\%) & 38.8 \\
\hline Soya lecithin & 1.00 & Digestible energy $(\mathrm{MJ} / \mathrm{kg})$ & $17 \cdot 7$ \\
\hline Vitamin E, premix (500 $000 \mathrm{lU} / \mathrm{kg}$ ) & 0.04 & DP:DE ratio (g/MJ) & $22 \cdot 0$ \\
\hline DL-Met & 0.20 & & \\
\hline Guar gum & 0.20 & & \\
\hline Vitamin premix (VIT-9608) & 1.00 & & \\
\hline Mineral premix (MIN-9504) & 0.50 & & \\
\hline Fish oil & 8.00 & & \\
\hline Plant oil & 5.00 & & \\
\hline
\end{tabular}

$\mathrm{CP}$, crude protein; $\mathrm{DP}$, digestible protein; $\mathrm{DE}$, digestible energy.

Resources feed contract. The diet was re-pelleted to $5 \mathrm{~mm}$ for the juveniles and $1 \mathrm{~mm}$ for the fingerlings. The highest restriction level was chosen because it approximately supports maintenance energy requirements and still allows some (protein) growth ${ }^{(17)}$. All fish were fed twice a day for 6 weeks. At the beginning of the trial, satiation ration was determined for both age groups by manual feeding, and rations for the other groups were subsequently calculated. Rations were re-estimated twice per week.

\section{Sampling}

Before stocking the tanks, initial samples were taken: seventyseven fingerlings $(100 \mathrm{~g})$ were sampled and frozen in four pools of $25 \mathrm{~g}$ for proximate analysis. At the same time, another ten fish were sampled, measured and weighed, and fixed in Serra's solution (absolute ethanol: six volumes; $37 \%$ formalin: three volumes; glacial acetic acid: one volume) and kept at $4^{\circ} \mathrm{C}$ until transferred to $n$-butanol pending histological analysis ${ }^{(34)}$. All fish were killed using an overdose of buffered MS-222. Similarly, six juvenile fish were killed and immediately frozen $\left(-80^{\circ} \mathrm{C}\right)$ until whole-body proximate analysis. An additional six juveniles were also sampled, weighed and measured, and dissected. The viscera were removed by separating the gill arches from the skull and pulling the gills, heart, digestive system and gonads outside the body cavity. The rectum was then cut as closely to the skin as possible to remove the visceral mass. Finally, the kidneys were scraped off and added to the visceral pool. Fish were then carefully filleted with a scalpel in a dorso-ventral direction in order to leave the ribs on the carcass. The skin was carefully removed, after which the red muscle was separated from the white muscle. Each body compartment (i.e. viscera, white muscle, red muscle and rest of the carcass) was weighed and bagged separately before being frozen $\left(-80^{\circ} \mathrm{C}\right)$, pending chemical analysis.

At 2 and 4 weeks' time, one juvenile per tank (i.e. $n 3$ per treatment) was randomly sampled, measured, weighed and dissected as described above. Additionally, three fingerlings per tank (i.e. $n 9$ per treatment) were randomly sampled, measured, weighed and fixed in Serra's solution (absolute ethanol: six volumes; $37 \%$ formalin: three volumes; glacial acetic acid: one volume) for histological analysis. Finally, upon trial termination (6 weeks), three juveniles per treatment were sampled for tissue dissection and twelve additional fish were frozen $\left(-80^{\circ} \mathrm{C}\right)$ whole for proximate analysis. A total of nine fingerlings per treatment were randomly sampled, measured, weighed and fixed in Serra's solution for histological analysis, while forty-five additional fish per treatment were pooled and frozen $\left(-80^{\circ} \mathrm{C}\right)$ for proximate analysis.

\section{Laboratory analyses}

Fingerling histology. For histological analysis, each fish was cross-sectioned in six places: at the pectoral girdle; the anterior insertion point of the dorsal fin; the anus; the dorsal and ventral insertion points of the caudal fin segments (Fig. 1(a)). The sections were dehydrated and embedded in paraffin. Ensuing histological slides ( $6 \mu \mathrm{m}$ thick) were stained with haematoxylin and orange $G^{(35)}$. Histological slides were digitised, and the surface areas of the white and red muscles were measured using ImageJ (US National Institutes of Health, http://imagej. nih.gov/ij/). Additionally, the cellularity of white and red fibres was established according to the protocol developed by Alami-Durante et $a l^{(36)}$. Specifically, in section 4, all fibres in the dorsal red muscle were counted and measured. A subsampling area was determined in the white muscle to standardise the measurement of fibre diameters (Fig. 1(b)) Fibre count was extrapolated to the entire section based on the measured surface area of the white muscle.

SDS-PAGE of the white and red muscles of juveniles. White and red muscle samples of juveniles were analysed for total protein profile. A sample of fresh muscle (1 g) was homogenised in $0.6 \mathrm{M}-\mathrm{NaCl}$ solution $(1: 3, \mathrm{w} / \mathrm{w})$ using an iced mortar and pestle. The resulting slurry was then centrifuged at $21300 \mathrm{~g}$ (middle of the tube) for $20 \mathrm{~min}$ at $4{ }^{\circ} \mathrm{C}$. The supernatant was analysed for total N (Leco-FP528; Leco Corporation), and the samples were diluted to $2 \mathrm{mg}$ protein 

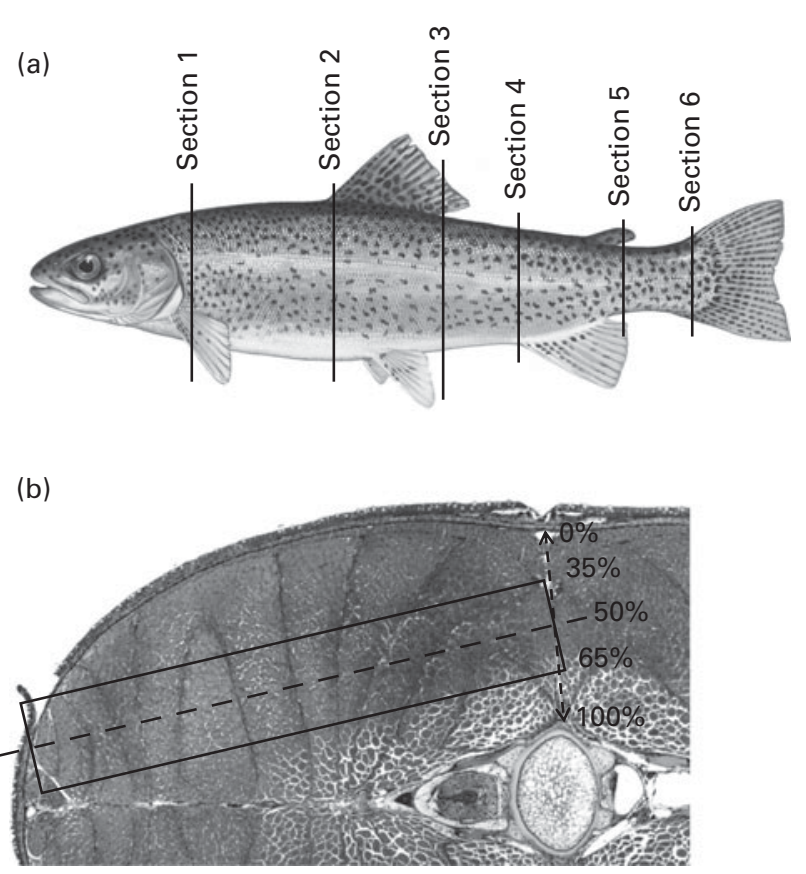

Fig. 1. Location of histological sampling: (a) location of cross-sections and (b) subsampling zone for the measurement of individual white muscle fibres.

per $\mathrm{ml}$ with a derivatising solution (15 mm-Tris $8.8,2.5 \%$ SDS, 5\% mercaptoethanol and $0.01 \%$ bromophenol blue). The samples were then placed in boiling water for $5 \mathrm{~min}$ and stored in a fridge until separation by gel electrophoresis. Electrophoresis was conducted using a PhastSystem (GE Healthcare) and pre-cast stacking gels (PhastGel Homogeneous 20). On each gel, two standard ladders (range $14 \cdot 5-220 \mathrm{kDa})$ were run. After completion of the separation, the gels were stained using Coomassie staining solution.

Proximate analyses. Samples collected for proximate analyses were autoclaved, ground into homogeneous slurry, freeze-dried, homogenised and stored at $-20^{\circ} \mathrm{C}$ until analysis. Analyses included DM (since freeze-drying dries the samples incompletely) and ash according to the guidelines of the Association of Official Analytical Chemists ${ }^{(37)}$, crude protein (CP, $\% \mathrm{~N} \times 6.25$ ) using Leco-FP528, and total lipid according to the method of Bligh \& Dyer ${ }^{(38)}$. The ash content of red muscle samples could not be determined due to limited amounts of tissue. The gross energy content of whole-carcass samples was measured using an automated bomb calorimeter (Model 1272; Parr Instruments). Gross energy content was not analysed in body compartment samples due to limited amounts of tissue.

\section{Calculations and statistical analysis}

Growth rates were calculated as thermal-unit growth coefficients (TGC) $)^{(39,40)}$.

$$
\mathrm{TGC}=\frac{\mathrm{FBW}^{1 / 3}-\mathrm{IBW}^{1 / 3}}{\sum^{d} T_{d}} \times 100,
$$

where FBW is the individual final body weight (g), IBW is the individual initial body weight $(\mathrm{g})$ and $T$ is the average water temperature for the day $(d)$.
Since individual fish were dissected and analysed, individual FI $\left(\mathrm{g} / \mathrm{kg}^{0-8}\right)$ had to be estimated. However, social interactions (e.g. dominance) prevented us from assuming that the tank ration was equally distributed between the fish. Therefore, FI was estimated based on the regression of TGC against FI using tank-based data over the entire trial. The regression equations were as follows:

$$
\begin{gathered}
\text { For juveniles: } \mathrm{FI}=111 \cdot 19 e^{6.1392 \times \mathrm{TGC}}\left(R^{2} 0 \cdot 9846\right), \\
\text { For fingerlings: } \mathrm{FI}=89.977 e^{11 \cdot 171 \times \mathrm{TGC}}\left(R^{2} 0.9892\right) .
\end{gathered}
$$

Upon sampling, individual fish were weighed, which allowed for the calculation of an individual TGC and then for the estimation of FI since the beginning of the trial. Maintenance rations were estimated by extrapolation of the above equations, solving for $\mathrm{TGC}=0$. Thus, maintenance ration for juveniles was $2.6 \mathrm{~g} / \mathrm{kg}^{0.8}$ per $\mathrm{d}$ and that for fingerlings was $2 \cdot 1 \mathrm{~g} / \mathrm{kg}^{0.8}$ per $\mathrm{d}$.

All the results were subjected to statistical analysis using SPSS 19 (IBM). Results were deemed significant when $P<0.05$, unless otherwise stated. The results obtained for the effect of treatments on proximate composition of the fish, nutrient deposition, SDS-PAGE and muscle histology (surface area and cellularity) were subjected to multiple regression analyses. Regression models between treatment levels were tested for uniformity of slope and intercept by ANCOVA $^{(41)}$ before running the regression across all the treatments (data not shown).

\section{Results}

\section{Growth performance}

The growth performance of both the fingerling and juvenile groups reflected the graded levels of feed restriction. At the end of the trial, the average individual weights of fish in the 100 and $25 \%$ feeding groups were $175 \cdot 2$ and $100 \cdot 5 \mathrm{~g}$ for juveniles and 5.8 and $2.5 \mathrm{~g}$ for fingerlings. Growth rates (expressed as TGC) increased with FI, ranging from 0.048 to 0.115 in fingerlings and from 0.098 to $0 \cdot 248$ in juveniles. However, this increase slowed down at the highest feeding level. This was confirmed by a significant quadratic relationship between TGC and FI (fingerlings: $R^{2}$ 0.990, $P<0.0001$; juveniles: $R^{2}$ 0.995, $\left.P<0.0001\right)$. Additionally, the plateau was more pronounced in the juveniles than in the fingerlings. FE were also significantly affected in a quadratic fashion. However, in juveniles, FE was decreased only in the highly fed fish (1.22-1.32 in the $25-75 \%$ feeding groups; $1.06 \%$ in the $100 \%$ feeding group), whereas in fingerlings, it was significantly higher in fish in the 50 and $75 \%$ feeding groups (1.23-1.25 in the 25 and $100 \%$ feeding groups; $1.38-1.41$ in the 50 and $75 \%$ feeding groups). Overall mortality was $4.5 \%$ in fingerlings, without significant differences between the feeding groups. No mortality was recorded in the juveniles.

\section{Whole-fish composition}

Fig. 2 shows the correlations between FI and whole-carcass compositions of fingerlings and juveniles at the end of the 

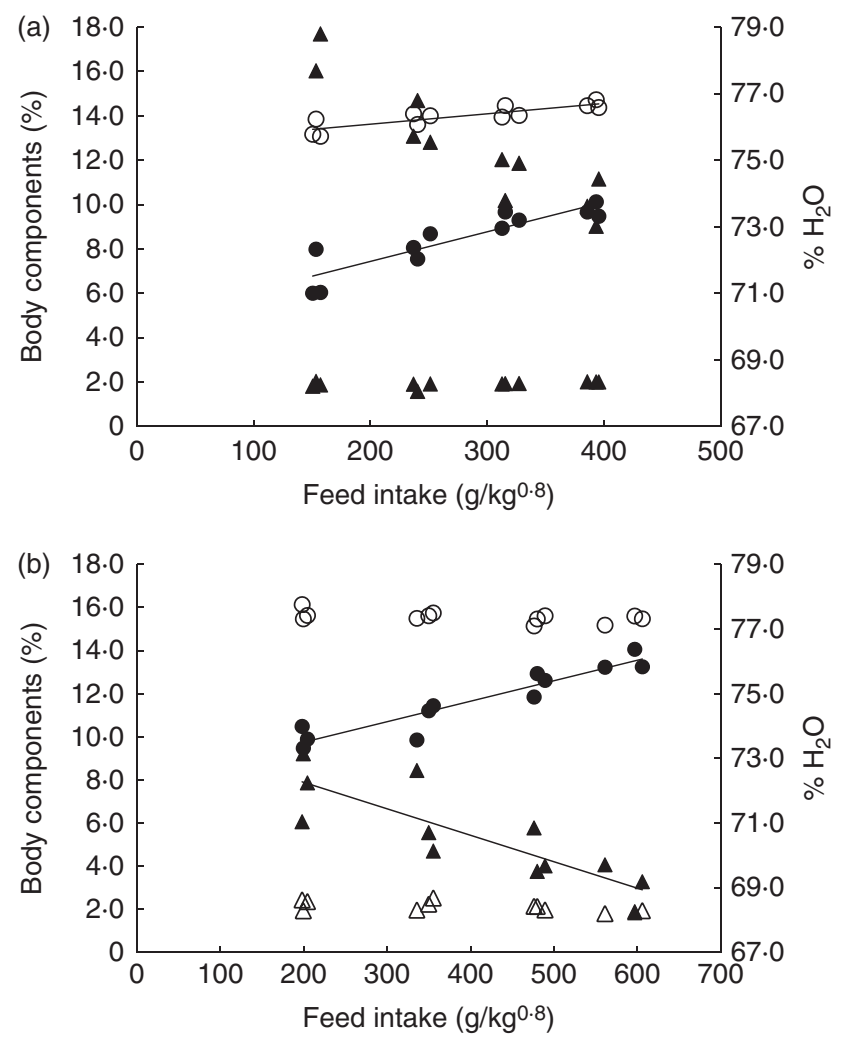

Fig. 2. Whole-carcass composition of fingerlings (a) and juveniles (b) at the end of the trial. $\bigcirc$, Crude protein; $\bullet$, lipid; $\Delta$, ash; $\boldsymbol{\Lambda}$, water.

trial. In juveniles, water and lipid contents exhibited opposite trends with regard to FI: as the former decreased, the latter increased with higher intake. Although a similar relationship was observed in fingerlings, multiple linear regression analysis indicated that body weight was the only significant factor correlated with body water content. The $\mathrm{CP}$ content of fingerlings and crude lipid content of both juveniles and fingerlings were significantly affected by FI $(P<0 \cdot 001 ;$ Table 2$)$. The energy content of juveniles reflects the impact of FI on CP and lipid contents, and thus it was also significantly affected by FI. Contrarily, the water and energy contents of fingerlings were significantly correlated only with body weight. Finally, the protein content in juveniles and the ash content in both juveniles and fingerlings were not significantly affected by body weight or FI (Table 2).

\section{Nutrient accretion in the body compartments of juveniles}

Fig. 3 shows the nutrient accretion in each of the four body compartments against FI. The deposition of all nutrients showed positive correlations with FI, and no nutrient loss (negative deposition) was observed, including at the lowest FI levels. Regardless of the body compartment, ash was the least-deposited nutrient. Conversely, water was mostly deposited in the white and red muscles along with proteins, whereas lipids were mostly deposited in the viscera.

The data were further analysed using multiple isometric regression analysis. Indeed, allometric regressions yielded higher residuals than isometric regressions (data not shown), in accordance with previous reports ${ }^{(22)}$. Nutrient accretion was tested against body weight and FI and their interaction. Results revealed that FI alone was not a significant factor (Table 3): the accretion of proteins, lipids and ash in the white muscle, ash in the viscera, and proteins in the rest of the carcass was significantly affected by the interaction of body weight and FI $\left(R^{2} 0 \cdot 719-0 \cdot 970, P<0 \cdot 001\right)$. The accretion of all the other nutrients was significantly correlated only with body weight $\left(R^{2} 0 \cdot 543-0 \cdot 950, P<0 \cdot 001\right)$.

\section{Protein profile in the red and white muscles of juveniles}

In the SDS-PAGE of white muscle samples, twenty-one bands with molecular weights ranging from 8.7 to $224.7 \mathrm{kDa}$ were separated. In the SDS-PAGE of red muscle samples, nineteen bands with molecular weights ranging from 14.0 to $233.6 \mathrm{kDa}$ were separated. The bands can be grouped based on the results of multiple regression analyses of accretion $v$. body weight and FI (Table 4). In the white muscle, four different patterns were observed. In the white muscle, the deposition of most of the bands (nine of twenty-one; first pattern in Table 4) was significantly correlated only with body weight $(P<0 \cdot 001)$, while six other bands (second pattern in Table 4) were significantly correlated with neither factor. In the third pattern, the deposition of four bands (20, 40, 45 and $173 \mathrm{kDa}$ ) was positively correlated with body weight, but negatively correlated with FI $(P<0 \cdot 05)$. Finally, only two bands (22 and $32 \mathrm{kDa}$ ) were significantly correlated with only FI $(P<0.01)$.

In the red muscle, all but one band were significantly correlated with only body weight $(P<0.05)$. The $98 \mathrm{kDa}$ band was positively correlated with body weight and negatively correlated with FI $(P<0 \cdot 001)$.

\section{Fingerling histology}

Histological analysis of the muscles of fingerlings indicated differences in muscle growth patterns. Figure 4(a) and (b) shows the changes in total surface area of white muscle and red muscle, respectively, in each of the six cross-sections. The cross-sectional surface areas of the white muscle increased with FI in a logarithmic fashion $(P<0 \cdot 0001)$, while

Table 2. Statistical results of stepwise linear regression of whole-body composition (g) $v$. feed intake ( $\mathrm{Fl} ; \mathrm{g} /$ fish) at the end of the 6-week trial

\begin{tabular}{lcccc}
\hline & Fish size & $R^{2}$ & $P$ & Significant factor \\
\hline Water & $\mathrm{F}$ & 0.881 & $<0.001$ & $\mathrm{BW}$ \\
\multirow{2}{*}{ Crude protein } & $\mathrm{J}$ & 0.695 & $<0.001$ & $\mathrm{FI}$ \\
& $\mathrm{F}$ & 0.731 & $<0.001$ & $\mathrm{FI}$ \\
Crude lipid & $\mathrm{J}$ & 0.203 & $\mathrm{NS}$ & - \\
& $\mathrm{F}$ & 0.794 & $<0.001$ & $\mathrm{FI}$ \\
Ash & $\mathrm{J}$ & 0.868 & $<0.001$ & $\mathrm{FI}$ \\
& $\mathrm{F}$ & 0.172 & $\mathrm{NS}$ & - \\
Gross energy & $\mathrm{J}$ & 0.277 & $\mathrm{NS}$ & - \\
& $\mathrm{F}$ & 0.931 & $<0.001$ & $\mathrm{BW}$ \\
& $\mathrm{J}$ & 0.844 & $<0.001$ & $\mathrm{FI}$ \\
\hline
\end{tabular}

F, fingerling; BW, body weight; J, juvenile. 

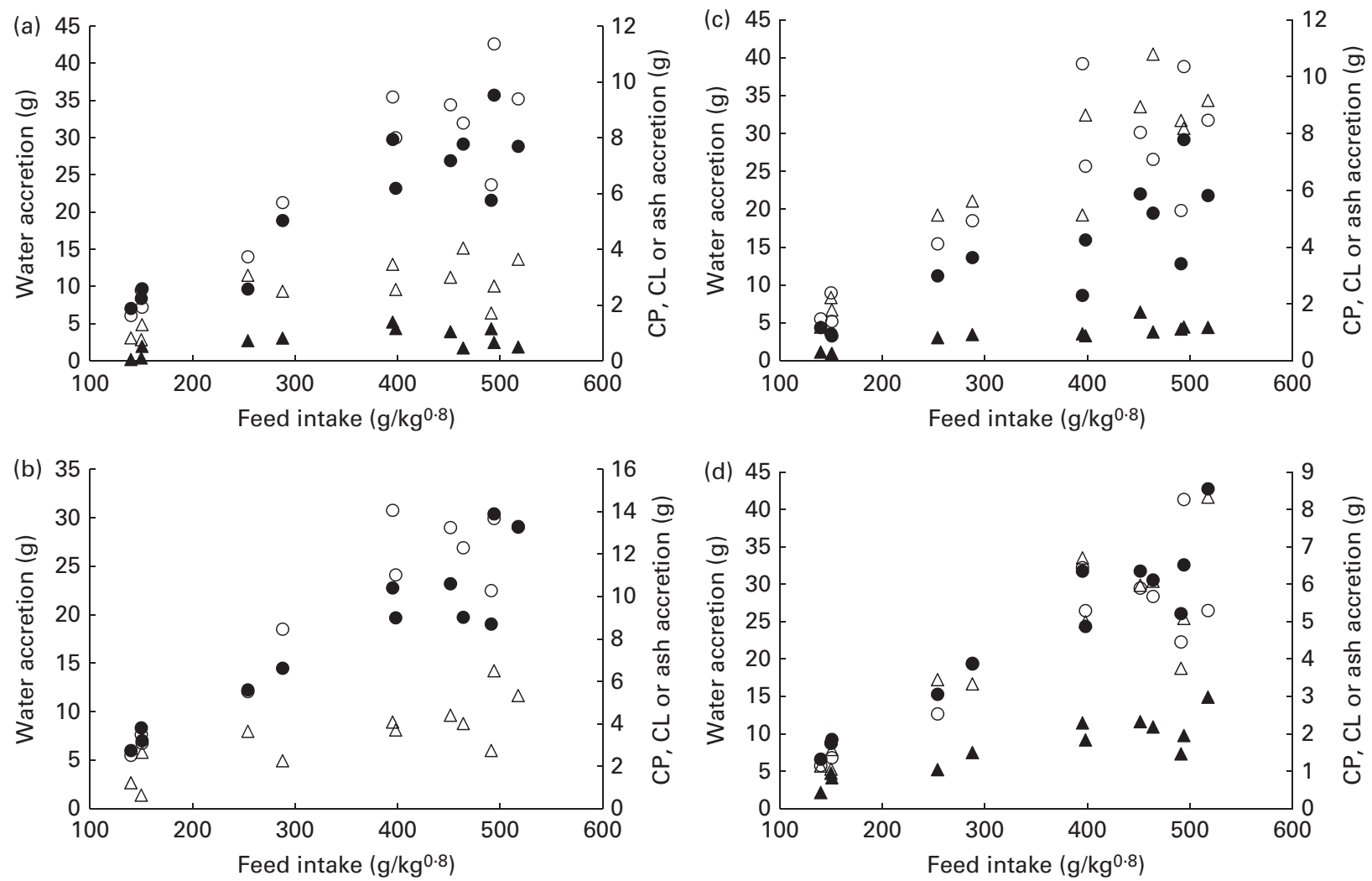

Fig. 3. Nutrient accretion in (a) white muscle, (b) red muscle, (c) viscera and (d) rest of the carcass during the entire trial. $\mathrm{O}$, Water; $\bullet$, crude protein (CP); $\Delta$, crude lipid (CL); $\mathbf{\Lambda}$, ash.

those of the red muscle increased more linearly $(P<0 \cdot 001)$. Stepwise multiple regression analyses (surface areas $v$. body weight, FI, fish height, fish total length and fish condition factor) for each of the six sections showed that the four anterior sections were significantly affected by FI, while the two most posterior sections were not (Table 5). Fish body weight was not a significant factor.

Table 6 summarises the results of stepwise multiple regressions of fibre diameter and number in the red and white muscles located in section 4: total fish length was the sole significant predictor of the mean and median fibre diameter in the white muscle, as well as the diameter of the five biggest white fibres. Body weight was the only significant factor when regressing against the number of fibres. In contrast, in the red muscle, all husbandry variables were non-significant for all cellular variables except for the number of fibres. Changes in fibre number and diameter for the four dietary levels are shown in Fig. 5. In the white muscle, the number of fibres increased linearly as fish gained weight $(P<0.0001 ;$ Fig. 5(a)). Simultaneously, the average diameter of the five biggest white fibres showed a negative linear correlation with fish length $(P<0.0001$; Fig. 5(b)). Finally, a negative exponential relationship between the diameter of the biggest white fibres and their number was observed $(P<0.0001$; Fig. 5(c)). Additionally, highly restricted fish had fewer fibres but with higher maximum diameter compared with the highly fed fish. In the red muscle, the number of fibres also increased linearly with body weight $(P<0 \cdot 0001$; Fig. 5(a)). However, there was no significant correlation between fish length and the diameter of the five biggest fibres (Fig. 5(b)) or between the diameter of the biggest fibres and the number of red fibres (Fig. 5(c)).

\section{Discussion}

Feed restriction has been shown to influence physiology and metabolism in fish ${ }^{(42-44)}$. However, most studies were limited

Table 3. Statistical results of stepwise linear regression of nutrient accretion in body compartments at the end of the 6-week trial

\begin{tabular}{lcccc}
\hline & & $R^{2}$ & $P$ & Significant factor \\
\hline White muscle & Water & 0.950 & $<0.001$ & $\mathrm{BW}$ \\
& $\mathrm{CP}$ & 0.946 & $<0.001$ & $\mathrm{BW} \times \mathrm{FI}$ \\
& $\mathrm{CL}$ & 0.821 & $<0.001$ & $\mathrm{BW} \times \mathrm{FI}$ \\
Red muscle & Ash & 0.719 & $<0.001$ & $\mathrm{BW} \times \mathrm{FI}$ \\
& Water & 0.941 & $<0.001$ & $\mathrm{BW}$ \\
Viscera & $\mathrm{CP}$ & 0.822 & $<0.001$ & $\mathrm{BW}$ \\
& $\mathrm{CL}$ & 0.543 & $<0.001$ & $\mathrm{BW}$ \\
& Water & 0.923 & $<0.001$ & $\mathrm{BW}$ \\
& $\mathrm{CP}$ & 0.825 & $<0.001$ & $\mathrm{BW}$ \\
Rest of the carcass & $\mathrm{CL}$ & 0.842 & $<0.001$ & $\mathrm{BW}$ \\
& $\mathrm{Ash}$ & 0.839 & $<0.001$ & $\mathrm{BW} \times \mathrm{FI}$ \\
& Water & 0.934 & $<0.001$ & $\mathrm{BW}$ \\
& $\mathrm{CP}$ & 0.970 & $<0.001$ & $\mathrm{BW} \times \mathrm{FI}$ \\
& $\mathrm{CL}$ & 0.892 & $<0.001$ & $\mathrm{BW}$ \\
& $\mathrm{Ash}$ & 0.907 & $<0.001$ & $\mathrm{BW}$ \\
& & & & \\
& & &
\end{tabular}

BW, body weight; $\mathrm{CP}$, crude protein; $\mathrm{Fl}$, feed intake $\left(\mathrm{g} / \mathrm{kg}^{0.8}\right.$ per 6 weeks); $\mathrm{CL}$, crude lipid. 
Table 4. Results of linear multiple regression analysis of muscle protein separation by SDS-PAGE: correlation with body weight and feed intake (FI)

\begin{tabular}{|c|c|c|c|c|c|c|}
\hline \multirow[b]{2}{*}{ Protein bands (kDa) } & \multicolumn{4}{|c|}{ White muscle } & \multicolumn{2}{|c|}{ Red muscle } \\
\hline & $\begin{array}{c}13 \cdot 7,18,23,25,28,35 \\
55,86,122\end{array}$ & $13 \cdot 1,14,16,21,66,144$ & $20,40,45,173$ & 22,32 & 98 & All other bands \\
\hline$R^{2}$ & $0.296-0.675$ & & $0.234-0.841$ & $0.235-0.640$ & 0.711 & $0.127-0.790$ \\
\hline$P$ & $<0.001$ & NS & $<0.05$ & $<0.01$ & $<0.001$ & $<0.05$ \\
\hline BW & + & NS & + & NS & + & + \\
\hline $\mathrm{FI}$ & NS & NS & - & + & - & NS \\
\hline
\end{tabular}

BW, body weight; + , positively correlated with protein(s) accretion; - , negatively correlated with protein(s) accretion.

to whole fish or a single body compartment. The main goal of the present study was to gain a more comprehensive view of nutrient deposition patterns in response to varying levels of FI. The results shed light on the adaptive strategy of fish, which organ group is prioritised and how these priorities change as fish grow in size.

\section{Effect on tissue and organ growth}

At the whole-fish level, proximate composition was significantly affected by the dietary treatment. In accordance with previous studies ${ }^{(19,45,46)}$, we observed the well-described water/lipid negative correlation in both the size classes and a stable protein content in juveniles. Nevertheless, in the present study, there was a positive deposition of all nutrients, including lipids, in all the experimental groups, as well as positive growth and good FE. Thus, even the lowest feeding level was above the maintenance level, and the fish were neither wasted nor cachectic ${ }^{(26)}$. However, we did not observe negative energy retention as Bureau et al. ${ }^{(17)}$ did when using a similar experimental protocol. This loss of energy was driven by lipid mobilisation at the end of the 24-week trial. There are limitations in expressing feed restriction as a proportion of near-satiation intake due to variability in the latter parameter. It is possible that we would have obtained similar results if the trial had been extended. This suggests that trout are able to withstand heavy feed restriction (about 25\% of satiation ration) for extended periods of time.

The bioenergetics model predicts a gradual decrease in FE as the metabolisable energy intake decreases ${ }^{(47,48)}$. However, FE was only marginally affected by feeding rations. In both the size classes, the best FE were observed in the moderate feed restriction groups (50 and 75\% feeding groups: $250-$ 320 and $350-480 \mathrm{~g}$ feed $/ \mathrm{kg}^{0.8}$ for fingerlings and juveniles, respectively), while lower FE were observed in fish fed to satiation. This is consistent with the results of the study carried out by Cleveland \& Burr ${ }^{(49)}$, who reported best $\mathrm{FE}$ at $75 \%$ satiation and a significant decrease at $100 \%$ satiation. However, the authors also observed a strongly decreased FE $(52 \%)$ in their most-restricted group (52\% at $20 \%$ feed ration), which corresponded to an intake of $33.1 \mathrm{~kJ} / \mathrm{kg}^{0.8}$ per $\mathrm{d}$ on a digestible energy basis. FE increased to $96-98 \%$ in the other groups fed $58.4 \mathrm{~kJ} / \mathrm{kg}^{0.8}$ per $\mathrm{d}$ and above. In contrast, we did not observe such a drastic decrease in $\mathrm{FE}$ in highly restricted groups in juveniles (FE range 96.9$120 \cdot 8 \%$ ) or in fingerlings (FE range $120 \cdot 8-139 \cdot 1 \%$ ). However, the lowest intakes were 84.5 and $64.7 \mathrm{~kJ} / \mathrm{kg}^{0.8}$ per $\mathrm{d}$ in the juveniles and fingerlings, respectively, which are higher than those reported by Cleveland \& Burr ${ }^{(49)}$. This is due to higher dietary protein and lipid contents, which resulted in a more energy-dense diet. Therefore, it is likely that the marked drop in FE as observed by Cleveland \& Burr ${ }^{(49)}$ is due to a higher level of feed restriction compared with that employed in the present study.

The present study also highlights differences in how fish from the two size classes react to feed restriction. FE decreased significantly in groups fed highly restricted rations (25\%) in fingerlings but not in juveniles. This is probably due to the decrease in $\mathrm{CP}$ content in fingerlings, despite a remarkable increase in water content (Table 2; Fig. 2(a)). Dumas et al. ${ }^{(22)}$ also found that smaller fish have a lower CP content. Juveniles, on the other hand, maintain their body protein content and the increase in water content is sufficient to mask the
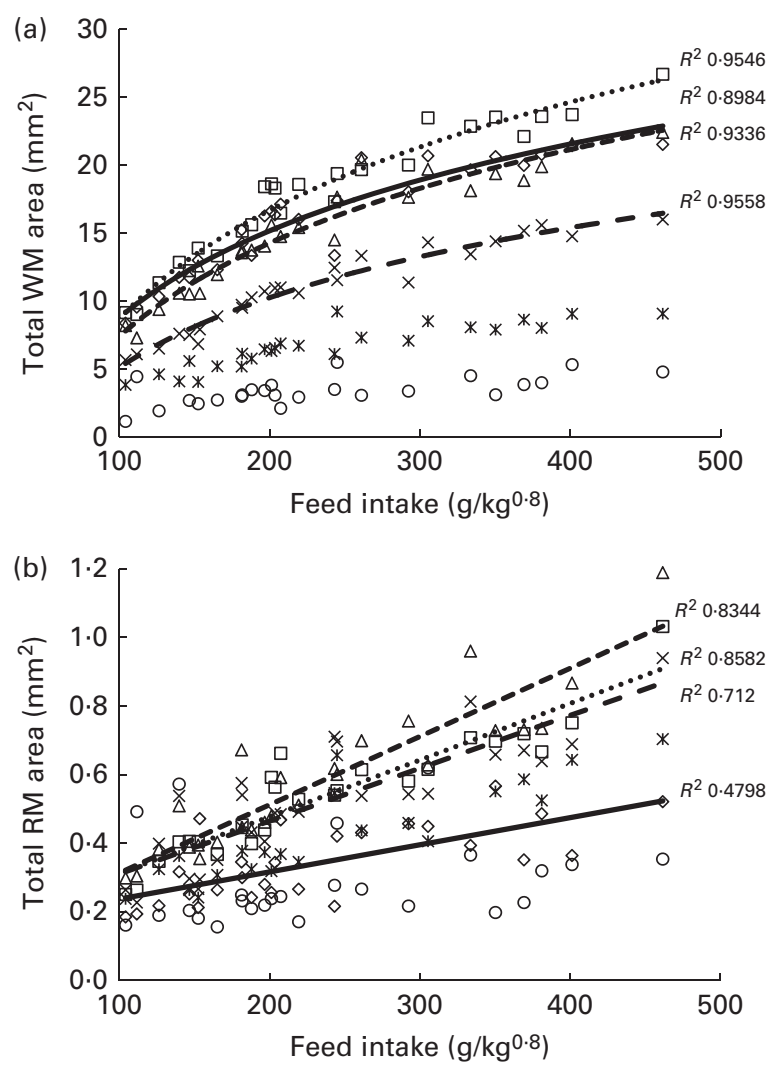

Fig. 4. Total surface area of (a) white muscle (WM) and (b) red muscle (RM) in the six cross-sections of fingerlings. $\diamond$, Section $1 ; \square$, section $2 ; \Delta$, section 3 ; $\times$, section $4 ; *$, section 5 ; $\bigcirc$, section 6 . 
Table 5. Statistical results of stepwise linear regression of muscle surface area in each of the six cross-sections at the end of the 6-week trial

\begin{tabular}{lcccc}
\hline & Section & $R^{2}$ & $P$ & Significant factor \\
\hline White muscle & 1 & 0.952 & $<0.001$ & $\mathrm{FI}, \mathrm{FH}$ \\
& 2 & 0.840 & $<0.001$ & $\mathrm{FI}, \mathrm{TL}$ \\
& 3 & 0.687 & $<0.001$ & $\mathrm{FI}$ \\
& 4 & 0.538 & $<0.001$ & $\mathrm{FI}$ \\
Red muscle & 5 & 0.944 & $<0.001$ & $\mathrm{FH}, K$ \\
& 6 & 0.051 & $\mathrm{NS}$ & - \\
& 1 & 0.614 & $<0.001$ & $\mathrm{FI}, \mathrm{FH}$ \\
& 2 & 0.782 & $<0.001$ & $\mathrm{FI}$ \\
& 3 & 0.765 & $<0.001$ & $\mathrm{FI}$ \\
& 4 & 0.568 & $<0.001$ & $\mathrm{FI}$ \\
& 5 & 0.628 & $<0.001$ & $\mathrm{FH}, K$ \\
& 6 & 0.155 & 0.046 & $\mathrm{FH}$
\end{tabular}

$\mathrm{Fl}$, feed intake $\left(\mathrm{g} / \mathrm{kg}^{0.8}\right.$ per 6 weeks); $\mathrm{FH}$, fish height $(\mathrm{mm}) ; \mathrm{TL}$, fish total length $(\mathrm{mm}) ; K$, condition factor.

loss of lipid mass. Therefore, they remain able to gain weight in such conditions, hence maintaining FE relatively stable. Additionally, water, protein, lipid and energy contents of juveniles were best described by FI, whereas body weight was the most significant factor explaining water and energy contents in fingerlings (Table 2). Thus, the body composition of fingerlings is more strongly driven by body weight than that of juveniles. This suggests that the priority for juveniles is to maintain their body protein content, whereas maintaining water and energy (i.e. balanced protein/lipid) contents would be more important for fingerlings.

\section{Effect on muscle protein profile}

The present study is the first study to describe a preferential accretion of specific proteins in the muscle in response to graded levels of FI. The present results indicate that the deposition of some proteins is simply influenced by body mass, while that of others is significantly affected by FI levels. This suggests that specific proteins can be utilised for catabolism, while some others are protected. This is the case, for instance, for the 20,40, 45 and $173 \mathrm{kDa}$ fractions in the white muscle and the $98 \mathrm{kDa}$ fraction in the red muscle: the deposition of these proteins is negatively correlated with FI. Therefore, they are preferentially deposited when FI is limited, whereas they account for a smaller proportion of deposition when FI is high. Since these fractions probably include proteins such as $\alpha$-actin ( $45 \mathrm{kDa}$ ) and subunits of myosin ( $173 \mathrm{kDa})$, these results suggest that the priority is logically given to the structural proteins of muscle core function. These results are in contrast with those obtained by Suárez et al. ${ }^{(45)}$, where graded levels of feeding restriction had only marginal, non-significant effects on the myofibrillar and sarcoplasmic protein fractions of the white muscle. However, this study used bigger fish (300-330 g) and restricted them for a shorter period of time ( $30 \mathrm{~d})$. Other studies described the effects of starvation on the preservation of white muscle proteins ${ }^{(50,51)}$ and also showed the preservation of myofibrillar proteins such as $\alpha$-actin.

Changes in myofibrillar and sarcoplasmic proteins are important, because they play a pivotal role in fillet quality characteristics, particularly firmness, that affect consumer acceptance and mechanical processing ${ }^{(52)}$. Attempts to control sensory characteristics (odour, texture, firmness, etc.) of fish fillet via manipulations of diet composition or swimming exercise resulted in limited effects ${ }^{(53-57)}$. However, feeding level may have a more significant effect, provided fish are restricted enough: in salmon, slight feed restriction ( $80 \%$ of satiation) has virtually no effect on fillet texture or lipid content ${ }^{(58)}$, whereas 50\%-restricted rainbow trout scored significantly lower for firmness and freshness of taste ${ }^{(59)}$. However, dedicated research is required to ascertain the relationship between these changes in protein profile and sensory quality of the edible muscle.

\section{Fingerlings: effect on muscle growth dynamics and cellularity}

Significant differences were observed in the number and diameter of muscle fibres, although FI level was always excluded during the stepwise process in favour of fish length and fish height (Table 6). Since FI level was a significant factor for muscle total surface area (Table 5), a change in fibre size distribution can be considered to be the mechanism by which nutritional status influences muscle size.

As expected, in both the muscles, we observed a linear increase in the number of fibres as the fish gained weight as a result of increasing ration (Fig. 5(a)). This illustrates the hyperplastic adaptation of muscle growth to feeding levels. However, differences between the white and red muscles arise when comparing maximum hypertrophy; in white muscles the maximum fibre diameter is lower in highly fed animals compared with restricted animals, whereas the maximum diameter remains stable in the red muscle regardless of feeding ration (Fig. 5(b)). These results suggest a higher priority for the conservation of the relative contribution of hyperplasia and hypertrophy to muscle growth in the red muscle in response to feed restriction and confirm previous findings that the white muscle is the vector of fish muscle plasticity ${ }^{(36,60)}$.

It is known that in fish, muscle grows both by hyperplasia and by hypertrophy at all ages ${ }^{(32,61)}$. However, muscle grows predominantly by hyperplasia in larvae and fingerlings and then mostly by hypertrophy as fish size increases ${ }^{(62,63)}$.

Table 6. Statistical results of stepwise linear regression of red and white muscle fibre cellularity at the end of the 6-week trial

\begin{tabular}{llccc}
\hline & Parameter & $R^{2}$ & $P$ & $\begin{array}{c}\text { Significant } \\
\text { factor }\end{array}$ \\
\hline White muscle & $D_{\text {mean }}$ & 0.4443 & 0.0001 & $\mathrm{TL}$ \\
& $D_{\text {median }}$ & 0.3996 & 0.0004 & $\mathrm{TL}$ \\
& $D_{5 \text { biggest }}$ & 0.4599 & 0.0002 & $\mathrm{TL}$ \\
& Fibre number & 0.5699 & $<0.0001$ & $\mathrm{BW}$ \\
Red muscle & $D_{\text {mean }}$ & - & - & None \\
& $D_{\text {median }}$ & - & - & None \\
& $D_{5 \text { biggest }}$ & - & - & None \\
& Fibre number & 0.7050 & $>0.0001$ & BW \\
\hline
\end{tabular}

$\mathrm{TL}$, fish total length (mm); BW, fish body weight $(\mathrm{g})$; $D_{\text {mean }}$, average fibre diameter; $D_{\text {median }}$, median fibre diameter; $D_{5}$ biggest, average diameter of the five biggest fibres.

* Stepwise models for $D_{\text {mean }}, D_{\text {median }}$ and $D_{5 \text { biggest }}$ in the red muscle excluded all the variable candidates; therefore, $R^{2}$ and $P$ values cannot be computed. 


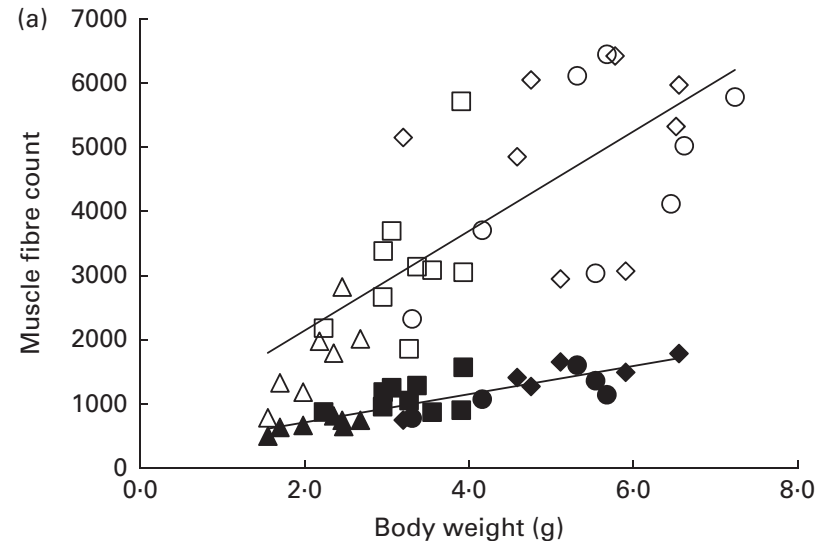

(b)
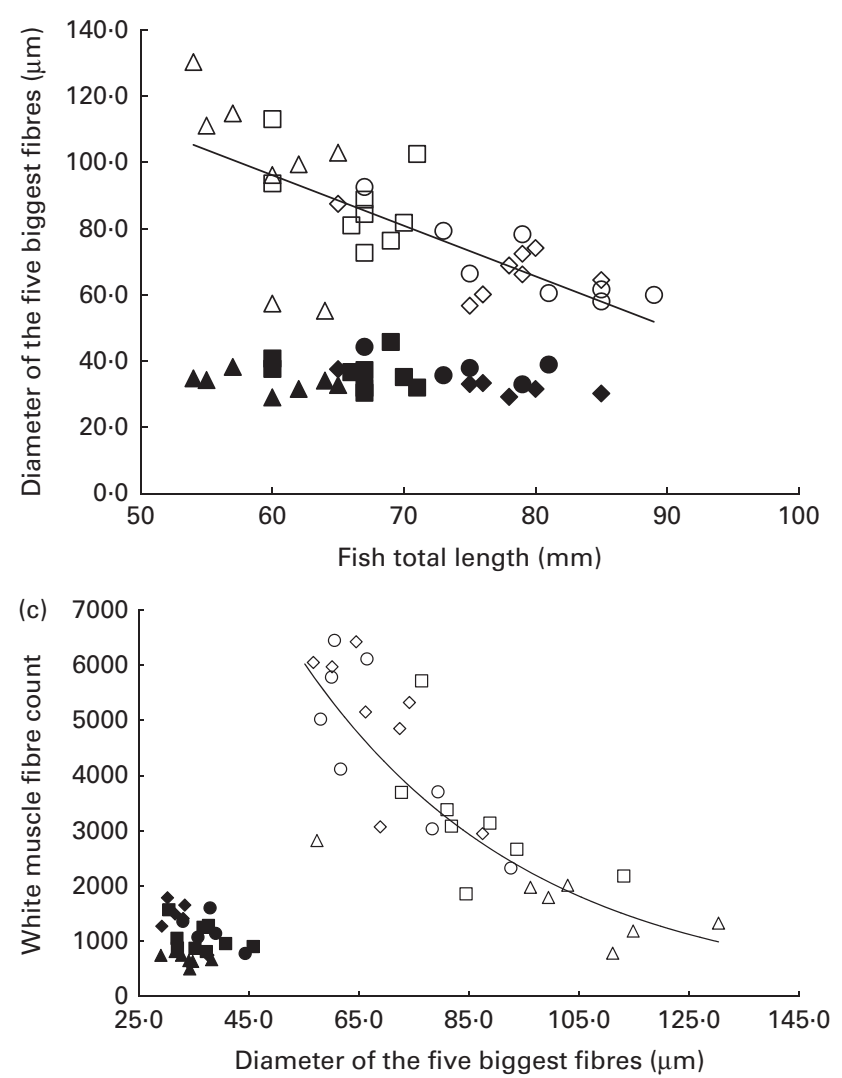

Fig. 5. Cellularity of the white muscle (WM) and red muscle (RM) fibres in fingerlings. (a) Number of WM and RM fibres $v$. body weight. WM fibres: linear regression, $R^{2} 0.5621, P<0.0001 ; y=776.38 x+588.95$. RM fibres: linear regression, $R^{2} 0.7050, P<0.0001 ; y=219.76 x+271.03$. (b) Diameter of the five biggest RM and WM fibres $v$. fish length. WM fibres: linear regression, $R^{2} 0.5628, P<0.0001 ; y=-1.5278 x+187.85$. RM fibres: no significant correlation $(P>0.05)$. (c) Number of RM and WM fibres $v$. diameter of the five biggest fibres. WM fibres: exponential regression, $R^{2} 0.7465, P<0.0001 ; y=22735 e^{-0.024 x}$. RM fibres: no significant correlation ( $P>0.05$ ). $\Delta$, WM $25 \%$; $\square$, WM $50 \%$; $\diamond$, WM $75 \%$; O, WM $100 \%$; $\boldsymbol{\Delta}$, RM $25 \%$; , RM $50 \%$;

The present study shows that highly fed fish have more white fibres and a lower maximum hypertrophy than low-fed fish, which is not observed in the red muscle (Fig. 5(c)). This suggests that FI mediates muscle growth by influencing the balance between hyperplasia and hypertrophy in the white muscle: low FI favours hypertrophy of existing fibres, while highly fed fish exhibit significantly heightened hyperplasia However, the fish strive to maintain red muscle cellularity, as shown by the lack of differences between the high and low levels of FI. These findings are in accordance with those obtained in carp larvae, juvenile rainbow trout and Atlantic salmon $^{(62,64,65)}$, where hypertrophy in the white muscle was favoured in slow-growing animals. However, this contrasts with findings in large, 2.5-year-old rainbow trout, where slow growth was associated with hyperplasia ${ }^{(32)}$. This may indicate a shift in the way the animal prioritises as it ages, thereby influencing its adaptive strategy to low food availability.

\section{Juveniles: coordination of nutrient utilisation between organ groups}

Overall, the results of the present study shed light on the coordinated metabolism between major groups of organs. First, body weight was always a significant factor in the analysis of nutrient deposition in the four body compartments, whether as the sole factor or through an interaction with FI. This overwhelming influence strongly suggests that the organism strives to reach a set nutrient deposition target. This is illustrated by the well-described stability of protein content at the whole-body level ${ }^{(22)}$. When FI becomes limited and achieving this target is hindered, priorities are set to selectively mobilise nutrient and groups of organ in favour of others. The present study demonstrates some of these priorities.

The present results indicate that the white muscle is the most-affected tissue when responding to feed restriction (Table 3). In fish, the muscle represents the bulk of the body (about $50 \%$ of the body weight in rainbow trout fingerlings and juveniles), hence a nutrient reserve as well. However, there are clear differences in mobilisation between the white and red muscles. This is illustrated by the nutrient accretion results as well as by the SDS-PAGE results; the red muscle is the only body compartment where body weight is the sole significant predictor of nutrient accretion (Table 3), while the SDS-PAGE results indicate that a single protein fraction is significantly affected by FI in the red muscle, compared with six fractions in the white muscle. Taken together, these results advocate for a priority of the red muscle over all other organs and especially over the white muscle. This can be explained by the function of the red muscle, the slow-twitch fibres of which allow for long-term, sustained swimming. On the other hand, the fast-twitch fibres of the white muscle allow for short-term, swift efforts such as attack or escape. The latter behaviours are of lesser priority compared with the ability to sustain swimming, which would explain the effort to preserve the red muscle. The metabolic difference between the red and white muscles is supported by previous studies, which described a differentiation in the metabolic substrate between white and red fibres ${ }^{(44)}$ : glycolysis is predominant in the white muscle of juveniles, while $\beta$-oxidation is mostly observed in the red muscle. Taken together with the nutrient deposition results of the present study, this suggests that lipids stored in the white muscle are mobilised to fuel the aerobic demands of the red muscle. 
Although visceral fat deposition was reduced as FI decreased (Fig. 3(c)), the finding that accretion of visceral lipids was only significantly affected by body weight (Table 3) was unexpected. This may have been otherwise if the trial had been run longer. Nevertheless, this suggests that muscle lipids are more labile in rainbow trout and are utilised before visceral fat during periods of restricted access to feed or food.

\section{Summary}

In conclusion, we provide evidence of priorities in growth and nutrient deposition in body compartments in response to FI levels in fish. At the whole-body level, juveniles strove to maintain body protein, while fingerlings prioritised water and energy contents. Although live body weight is a strong predictor of nutrient accretion, FI primarily affected the white muscle in juveniles while preserving the red muscle as well as the viscera. Specific proteins were preferentially deposited or mobilised in the muscle in response to varying feeding levels. Finally, fingerlings demonstrated adaptation to low feed availability by decreasing hyperplasia in favour of hypertrophy. Taken together, these results quantify the coordination between groups of organs in orchestrating the response to low food availability. They point to the differences in adaptation strategies between the two size classes studied in the present study. However, additional research will be necessary to incorporate these findings into the further development of nutritional models to accurately predict fish growth, FE and composition of edible products.

\section{Acknowledgements}

The authors thank Mashiur Rahman for his assistance with fish husbandry, as well as Marianne Cluzeaud and Susan Lapos for their help with the processing of histological samples. They also thank undergraduate students from the University of Guelph who assisted with some of the chemical and image analyses: Katrina Blackburn, Paige DeMarchi, Nancy-Gioia DeThomas and Samantha Jackson.

The present study was funded by the Ontario Ministry of Natural Resources (OMNR) and the Natural Sciences and Engineering Research Council of Canada (NSERC). Neither OMNR nor NSERC had a role in the design and analysis of the study or in the writing of this article.

The authors' contributions are as follows: G. S. and D. P. B. designed the experiment and led the project; G. S. conducted the feeding trial, collected and analysed the samples, and wrote the manuscript; H. A.-D. provided training and equipment for preparing histological slides and their interpretation; S. B. and M. M. provided training and equipment for SDS-PAGE and corresponding data interpretation. All authors contributed to manuscript preparation.

None of the authors has any conflicts of interest to declare.

\section{References}

1. Weatherley AH (1990) Approaches to understanding fish growth. Trans Am Fish Soc 119, 662-672.
2. Stroganov NS (1977) Role of environment in the plastic metabolism of fish. In Metabolism and Biochemistry of Fishes, pp. 35-47 [GS Karzin, editor]. New Delhi: Indian National Scientific Documentation Centre.

3. McClure CA, Hammell KL, Moore M, et al. (2007) Risk factors for early sexual maturation in Atlantic salmon in seawater farms in New Brunswick and Nova Scotia, Canada. Aquaculture 272, 370-379.

4. Shearer K, Parkins P, Gadberry B, et al. (2006) Effects of growth rate/body size and a low lipid diet on the incidence of early sexual maturation in juvenile male spring Chinook salmon (Oncorbynchus tshawytscha). Aquaculture 252, $545-556$.

5. Shearer KD \& Swanson P (2000) The effect of whole body lipid on early sexual maturation of $1+$ age male Chinook salmon (Oncorbynchus tshawytscha). Aquaculture 190, 343-367.

6. Brett JR (1979) Environmental factors and growth. In Fish Physiology. vol. VIII - Bioenergetics and Growth, pp. 599-675 [WS Hoar, DJ Randall and JR Brett, editors]. New York: Academic Press

7. Massou AM, Panfili J, Lae R, et al. (2002) Effects of different food restrictions on somatic and otolith growth in Nile tilapia reared under controlled conditions. J Fish Biol 60, 1093-1104

8. Mihelakakis A \& Kitajima C (1994) The effect of feeding level on growth and feed conversion in silver sea bream, Sparus sarba. J Fac Agric Kyushu Univ 39, 9-14.

9. Luo Z, Liu YJ, Mai KS, et al. (2006) Effects of feeding levels on growth performance, feed utilization, body composition, and apparent digestibility coefficients of nutrients for grouper Epinephelus coioides juveniles. J World Aquacult Soc 37, 32-40.

10. Ning NSP, Hladyz S, Gawne B, et al. (2012) Morphological, physiological and behavioural response patterns of carp gudgeon Hypseleotris spp. to food deprivation: implications for assessing health. J Fish Biol 80, 218-224.

11. Balint JP (1998) Physical findings in nutritional deficiencies. Pediatr Clin North Am 45, 245-260.

12. McCance RA \& Widdowson EM (1974) Review lecture: the determinants of growth and form. Proc R Soc Lond B Biol Sci 185, 1-17.

13. Kerr GR, Allen JR, Scheffler G, et al. (1970) Malnutrition studies in the rhesus monkey - I. Effect on physical growth. Am J Clin Nutr 23, 739-748.

14. Fleagle JG, Samonds KW \& Hegsted DM (1975) Physical growth of cebus monkeys, Cebus albifrons, during protein or calorie deficiency. Am J Clin Nutr 28, 246-253.

15. Zhan XA, Wang M, Ren H, et al. (2007) Effect of early feed restriction on metabolic programming and compensatory growth in broiler chickens. Poult Sci 86, 654-660.

16. Boaamponsem K, Dunnington EA \& Siegel PB (1991) Genotype, feeding regimen, and diet interactions in meat chickens. 1. Growth, organ size, and feed utilization. Poult Sci 70, 680-688.

17. Bureau DP, Hua K \& Cho CY (2006) Effect of feeding level on growth and nutrient deposition in rainbow trout (Oncorbynchus mykiss Walbaum) growing from 150 to 600 g. Aquaculture Res 37, 1090-1098.

18. Arzel J, Metailler R, Le Gall P, et al. (1998) Relationship between ration size and dietary protein level varying at the expense of carbohydrate and lipid in triploid brown trout fry, Salmo trutta. Aquaculture 162, 259-268.

19. Shearer KD (1994) Factors affecting the proximate composition of cultured fishes with emphasis on salmonids. Aquaculture 119, 63-88. 
20. Elliott JM (1976) Body composition of brown trout (Salmo trutta L.) in relation to temperature and ration size. J Anim Ecol 45, 273-289.

21. Love RM (1970) The Chemical Biology of Fishes. London: Academic Press.

22. Dumas A, de Lange CFM, France J, et al. (2007) Quantitative description of body composition and rates of nutrient deposition in rainbow trout (Oncorbynchus mykiss). Aquaculture 273, 165-181.

23. Azevedo PA, Cho CY, Leeson S, et al. (1998) Effects of feeding level and water temperature on growth, nutrient and energy utilization and waste outputs of rainbow trout (Oncorbynchus mykiss). Aquat Living Resour 11, 227-238.

24. Watanabe K, Ura K, Yada T, et al. (2000) Energy and protein requirements of yellowtail for maximum growth and maintenance of body weight. Fish Sci 66, 1053-1061.

25. Bureau DP \& Hua K (2008) Models of nutrient utilization by fish and potential applications for fish culture operations. In Mathematical Modelling in Animal Nutrition, pp. 442-461 [J France and E Kebreab, editors]. Wallingford, UK: CAB International.

26. Roubenoff R, Heymsfield SB, Kehayias JJ, et al. (1997) Standardization of nomenclature of body composition in weight loss. Am J Clin Nutr 66, 192-196.

27. Crawford RE (1979) Effect of starvation and experimental feeding on the proximate composition and caloric content of an Antarctic teleost, Notothenia coriiceps neglecta. Comp Biochem Physiol 62A, 321-326.

28. Black D \& Love RM (1986) The sequential mobilisation and restoration of energy reserves in tissues of Atlantic cod during starvation and refeeding. J Comp Physiol B 156, 469-479.

29. Dumas A, France J \& Bureau DP (2007) Evidence of three growth stanzas in rainbow trout (Oncorbynchus mykiss) across life stages and adaptation of the thermal-unit growth coefficient. Aquaculture 267, 139-146.

30. Sainz RD \& Bentley BE (1997) Visceral organ mass and cellularity in growth-restricted and refed beef steers. J Anim Sci 75, 1229-1236.

31. Blier PU, Dutil JD, Lemieux H, et al. (2007) Phenotypic flexibility of digestive system in Atlantic cod (Gadus morhua). Comp Biochem Physiol A Mol Integr Physiol 146, 174-179.

32. Kiessling A, Storebakken T, Åsgård T, et al. (1991) Changes in the structure and function of the epaxial muscle of rainbow trout (Oncorbynchus mykiss) in relation to ration and age: I. Growth dynamics. Aquaculture 93, 335-356.

33. NRC (2011) Nutrient Requirements of Fish and Shrimp. Washington, DC: National Academy Press.

34. Alami-Durante H (1990) Growth of organs and tissues in carp (Cyprinus carpio L.) larvae. Growth Dev Aging 54, 109-116.

35. Alami-Durante H, Olive N \& Rouel M (2007) Early thermal history significantly affects the seasonal hyperplastic process occurring in the myotomal white muscle of Dicentrarchus labrax juveniles. Cell Tissue Res 327, 553-570.

36. Alami-Durante H, Médale F, Cluzeaud M, et al. (2010) Skeletal muscle growth dynamics and expression of related genes in white and red muscles of rainbow trout fed diets with graded levels of a mixture of plant protein sources as substitutes for fishmeal. Aquaculture 303, 50-58.

37. AOAC (1995) Official Methods of Analysis, 15th ed. Arlington, VA: Association of Official Analytical Chemists.

38. Bligh EG \& Dyer WJ (1959) A rapid method of total lipid extraction and purification. Can J Biochem Physiol 37, 911-917.
39. Iwama GK \& Tautz AF (1981) A simple growth model for salmonids in hatcheries. Can J Fish Aquat Sci 38, 649-656.

40. Cho CY (1990) Fish nutrition, feeds, and feeding: with special emphasis on salmonid aquaculture. Food Rev Int $\mathbf{6}$, 333-357.

41. Snedecor GW \& Cochran WG (1967) Analysis of covariance In Statistical Methods, 6th ed., pp. 419-446. Ames, IA: Iowa State University Press.

42. Imsland AK \& Gunnarsson S (2011) Growth and maturation in Arctic charr (Salvelinus alpinus) in response to different feed rations. Aquaculture 318, 407-411.

43. Shikata T \& Shimeno S (1997) Regulation of carbohydrate metabolism in fish. 30. Effects of feed restriction and starvation on fatty acid synthesis and oxidation of glucose and alanine in carp hepatopancreas. Fish Sci 63, 301-303.

44. Kiessling A, Kiessling KH, Storebakken T, et al. (1991) Changes in the structure and function of the epaxial muscle of rainbow trout (Oncorbynchus mykiss) in relation to ration and age: II. Activity of key enzymes in energy metabolism. Aquaculture 93, 357-372.

45. Suárez MD, Martínez TF, Sáez MI, et al. (2010) Effects of dietary restriction on post-mortem changes in white muscle of sea bream (Sparus aurata). Aquaculture 307, 49-55.

46. Lupatsch I, Kissil GW, Sklan D, et al. (1998) Energy and protein requirements for maintenance and growth in gilthead seabream (Sparus aurata L.). Aquacult Nutr 4, 165-173.

47. Kaushik SJ \& Médale F (1994) Energy requirements, utilization and dietary supply to salmonids. Aquaculture 124, $81-97$.

48. Cho CY (1991) Prediction model for energy requirement of salmonid fishes. 12th Symposium of Energy Metabolism of Farm Animals No. 58, pp. 446-449.

49. Cleveland BM \& Burr GS (2011) Proteolytic response to feeding level in rainbow trout (Oncorbynchus mykiss). Aquaculture 319, 194-204.

50. Beaulieu MA \& Guderley H (1998) Changes in qualitative composition of white muscle with nutritional status of Atlantic cod, Gadus morbua. Comp Biochem Physiol A Mol Integr Physiol 121, 135-141.

51. Weber TE \& Bosworth BG (2005) Effects of 28 day exposure to cold temperature or feed restriction on growth, body composition, and expression of genes related to muscle growth and metabolism in channel catfish. Aquaculture 246, 483-492.

52. Godiksen H, Morzel M, Hyldig G, et al. (2009) Contribution of cathepsins B, L and D to muscle protein profiles correlated with texture in rainbow trout (Oncorbynchus mykiss). Food Chem 113, 889-896.

53. Mathis N, Feidt C \& Brun-Bellut J (2003) Influence of protein/energy ratio on carcass quality during the growing period of Eurasian perch (Perca fluviatilis). Aquaculture 217, 453-464.

54. Williams KC, Paterson BD, Barlow CG, et al. (2003) Potential of meat meal to replace fish meal in extruded dry diets for barramundi, Lates calcarifer (Bloch). II. Organoleptic characteristics and fatty acid composition. Aquacult Res $\mathbf{3 4}$, 33-42.

55. Bjørnevik M, Karlsen $\varnothing$, Johnston IA, et al. (2003) Effect of sustained exercise on white muscle structure and flesh quality in farmed cod (Gadus morhua L.). Aquacult Res 34, $55-64$.

56. Rasmussen RS, Heinrich MT, Hyldig G, et al. (2011) Moderate exercise of rainbow trout induces only minor differences in fatty acid profile, texture, white muscle fibres and proximate chemical composition of fillets. Aquaculture 314, 159-164. 
57. Rasmussen RS (2001) Quality of farmed salmonids with emphasis on proximate composition, yield and sensory characteristics. Aquacult Res 32, 767-786.

58. Young A, Morris PC, Huntingford FA, et al. (2005) The effects of diet, feeding regime and catch-up growth on flesh quality attributes of large $(1+$ sea winter $)$ Atlantic salmon, Salmo salar. Aquaculture 248, 59-73.

59. Johansson L, Kiessling A, Åsgård T, et al. (1995) Effects of ration level in rainbow trout, Oncorbynchus mykiss (Walbaum), on sensory characteristics, lipid content and fatty acid composition. Aquacult Nutr 1, 59-66.

60. Weatherley AH \& Gill HS (1987) The Biology of Fish Growth. London: Academic Press.

61. Weatherley AH, Gill HS \& Rogers SC (1980) The relationship between mosaic muscle fibres and size in rainbow trout (Salmo gairdneri). J Fish Biol 17, 603-610.
62. Alami-Durante H, Fauconneau B, Rouel M, et al. (1997) Growth and multiplication of white skeletal muscle fibres in carp larvae in relation to somatic growth rate. J Fish Biol 50, $1285-1302$

63. Koumans JTM, Akster HA, Booms GHR, et al. (1993) Growth of carp (Cyprinus carpio) white axial muscle; hyperplasia and hypertrophy in relation to the myonucleus/sarcoplasm ratio and the occurrence of different subclasses of myogenic cells. J Fish Biol 43, 69-80.

64. Higgins PJ \& Thorpe JE (1990) Hyperplasia and hypertrophy in the growth of skeletal muscle in juvenile Atlantic salmon, Salmo salar L. J Fish Biol 37, 505-519.

65. Weatherley AH, Gill HS \& Rogers SC (1979) Growth dynamics of muscle fibres, dry weight, and condition in relation to somatic growth rate in yearling rainbow trout (Salmo gairdneri). Can J Zool 57, 2385-2392. 